\title{
Predicting the success of endoscopic transpapillary gallbladder drainage for patients with acute cholecystitis during pretreatment evaluation
}

\author{
Osamu Ogawa MD, Hiroki Yoshikumi MD, Naotaka Maruoka PhD, Yusuke Hashimoto MD, \\ Yui Kishimoto MD, Watanabe Tsunamasa PhD, Yuichiro Kuroki MD, Hiroshi Yasuda PhD, \\ Yutaka Endo PhD, Kazuaki Inoue PhD, Makoto Yoshiba PhD
}

O Ogawa, H Yoshikumi, N Maruoka, et al. Predicting the success of endoscopic transpapillary gallbladder drainage for patients with acute cholecystitis during pretreatment evaluation. Can J Gastroenterol 2008;22(8):681-685.

INTRODUCTION: Although endoscopic transpapillary gallbladder drainage (ETGBD) has been reported to be an effective treatment for acute cholecystitis, technical difficulties have precluded more widespread use of this technique. Case evaluations that can predict the occurrence of such difficulties should increase the acceptance of ETGBD for acute cholecystitis treatment.

OBJECTIVE: To establish a pretreatment evaluation protocol for patients with acute cholecystitis.

METHODS: Eleven patients with acute cholecystitis who received ETGBD in 2003 or 2004 were enrolled in the present retrospective study. The frequency of success, complications and overall effectiveness of ETGBD for treatment of cholecystitis were measured. Factors that could affect ETGBD success, including clinical and laboratory parameters, and gallbladder ultrasonograms, were also evaluated.

RESULTS: ETGBD was successful in seven of 11 patients (success rate $63.6 \%$ ). All seven patients who underwent ETGBD successfully were afebrile and asymptomatic within a few days. No clinical or laboratory variables were significantly associated with the success of ETGBD. In contrast, ultrasonographic measures of gallbladder minor-axis length and wall thickness in successful cases were significantly shorter $(27.4 \mathrm{~mm}$ versus $38.0 \mathrm{~mm} ; \mathrm{P}=0.008)$ and thinner ( $4.2 \mathrm{~mm}$ versus $9.0 \mathrm{~mm} ; \mathrm{P}=0.041$ ) relative to unsuccessful cases.

CONCLUSIONS: Ultrasonographic measures of gallbladder minoraxis length and wall thickness can serve as important predictors of ETGBD technical difficulties during pretreatment evaluation of patients with acute cholecystitis.
Prévoir la réussite du drainage transpapillaire de la vésicule biliaire par voie endoscopique pour les patients atteints de cholécystite aiguë lors de l'évaluation prétraitement

INTRODUCTION : Même s'il est déclaré que le drainage transpapillaire de la vésicule biliaire par voie endoscopique (DTVBE) est un traitement efficace de la cholécystite aiguë, des problèmes techniques en ont empêché un usage plus généralisé. Des évaluations de cas en vue de prévoir l'occurrence de ces problèmes devraient rendre le DTVBE plus acceptable pour le traitement de la cholécystite aiguë.

OBJECTIF : Établir un protocole d'évaluation prétraitement pour les patients atteints de cholécystite aiguë.

MÉTHODOLOGIE : Onze patients atteints de cholécystite aiguë qui avaient subi un DTVBE en 2003 ou 2004 ont participé à la présente étude rétrospective. Les auteurs ont mesuré la fréquence des réussites, des complications et de l'efficacité globale du DTVBE. Ils ont également évalué les facteurs susceptibles d'influer sur la réussite du DTVBE, y compris les paramètres cliniques et de laboratoire et les échographies vésicales.

RÉSULTATS : Le DTVBE a réussi chez sept des 11 patients (taux de réussite de 63,6\%). Les sept patients qui ont subi un DTVBE réussi sont devenus afébriles et asymptomatiques au bout de quelques jours. Aucune variable clinique ou de laboratoire ne s'associait de manière significative à la réussite du DTVBE. Par contre, les mesures échographiques de la longueur du petit axe et de l'épaisseur de la paroi des cas réussis étaient beaucoup plus courtes $(27,4 \mathrm{~mm}$ par rapport à $38,0 \mathrm{~mm}$; $\mathrm{P}=0,008)$ et plus minces $(4,2 \mathrm{~mm}$ par rapport à $9,0 \mathrm{~mm} ; \mathrm{P}=0,041)$ que celles des cas non réussis.

CONCLUSIONS : Les mesures échographiques de la longueur du petit axe et de l'épaisseur de la paroi peuvent constituer des prédicteurs importants des problèmes techniques du DTVBE pendant l'évaluation prétraitement des patients atteints de cholécystite aiguë.

Key Words: Acute cholecystitis; Endoscopic transpapillary gallbladder drainage

$\mathrm{A}$ lthough the standard treatment for acute cholecystitis is acute cholecystectomy, patients with increased operative risk or serious local inflammation are susceptible to higher rates of morbidity and mortality due to cholecystectomy technical

difficulties $(1,2)$. Such surgically high-risk patients frequently require further medical treatments such as nonoral medications, intravenous fluids, antibiotics and analgesics, as well as close monitoring of blood pressure, pulse and urinary output.

Division of Gastroenterology, Showa University Fujigaoka Hospital, Aoba-ku, Yokohama, Japan

Correspondence and reprints: Dr Osamu Ogawa, Division of Gastroenterology, Showa University Fujigaoka Hospital, 1-30 Fujigaoka, Aoba-ku,

Yokohama 227-8501, Japan. Telephone 8-145-971-1151, fax 8-145-971-3824, e-mail o-ogawa@showa-university-fujigaoka.gr.jp

Received for publication May 1, 2008. Accepted May 23, 2008 


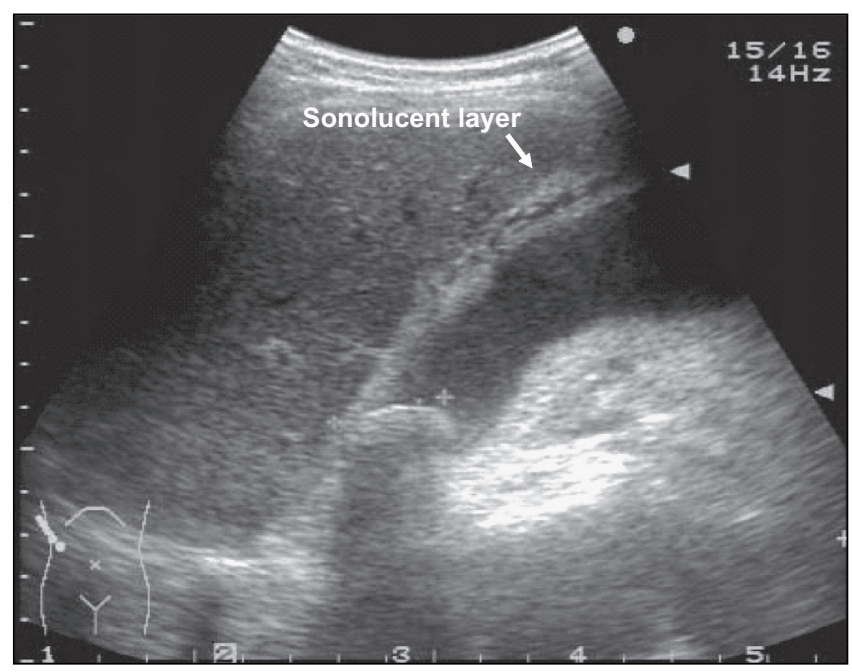

Figure 1) Sonolucent layer of the gallbladder

Percutaneus transhepatic gallbladder drainage (PTGBD) is an alternative therapy in cases in which medical treatment is not effective (3); however, PTGBD can also result in bile leakage, hepatic bleeding, tube dislodgement or tube occlusion (4-6), particularly in patients with ascites or coagulopathy (7). Endoscopic transpapillary gallbladder drainage (ETGBD) provides an appropriate treatment option for these high-risk patients.

ETGBD, which is an effective palliative short-term treatment for acute cholecystitis with only limited and mild complications, has the potential to avoid complications associated with PTGBD such as hematoma and biliary peritonitis $(8,9)$. However, ETGBD is not widely used because it is technically more difficult to perform, resulting in a lower success rate than PTGBD. One major factor contributing to the low success rate of ETGBD lies in the performance of the technique without adequate evaluation of associated technical difficulties. Pretreatment evaluation of a patient's condition and gallbladder is essential to avoid technical difficulties associated with ETGBD. Although a favourable pretreatment evaluation would allow ETGBD to be performed efficiently in appropriate patients, specific case parameters that are associated with a good outcome have yet to be identified. The objective of the present study was to establish a standard pretreatment evaluation protocol for patients with acute cholecystitis to more accurately predict the likelihood of ETGBD technical difficulties.

\section{METHODS}

Eleven patients with acute cholecystitis who underwent ETGBD in the Showa University Fujigaoka Hospital (Aoba-ku, Yokohama, Japan) between 2003 and 2004 were enrolled in the present retrospective study. All patients met the following criteria: physical findings showing right upper quadrant tenderness; blood tests showing systemic signs of inflammation (fever, and elevated C-reactive protein [CRP] or white blood cell levels); ultrasonographic findings showing the sonographic Murphy sign, thickening of the gallbladder wall or an enlarged gallbladder; and no evidence of any other disease (10).

Initially, the overall frequency of success, and complications and effectiveness of ETGBD were measured. Then, the

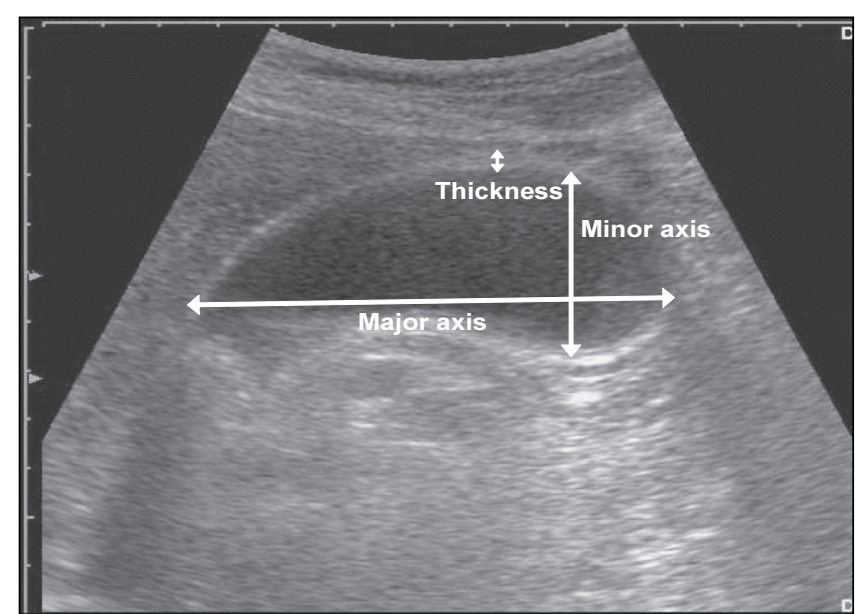

Figure 2) Gallbladder major-and minor-axis lengths, and wall thickness relationship of these outcomes with other factors that could affect the success of ETGBD was examined. These factors included age, sex, period from admission to ETGBD, history of cholecystitis and biliary colic, levels of CRP and white blood cells on admission, and ultrasonographic findings for the gallbladder including distension, sonolucent layer (Figure 1), dimensions of the major and minor axes, and thickness of the gallbladder wall (Figure 2). Statistically significant associations between these pretreatment parameters and occurrences in ETGBD-associated technical difficulties were then evaluated to identify predictors of ETGBD outcome. Statistical differences were measured using the $\chi^{2}$ test, two-sample $t$ test or Mann-Whitney $\mathrm{U}$ test, as appropriate. $\mathrm{P}<0.05$ indicated statistically significant differences.

\section{RESULTS}

ETGBD was successful in seven of 11 patients (success rate $63.6 \%$ ). All seven patients became afebrile and asymptomatic within a few days and were discharged within a mean of 15 days (Table 1). PTGBD was performed on the remaining four patients in whom ETGBD was unsuccessful, and a cystic duct perforation was detected in one patient. The recoveries of the four patients receiving PTGBD were also uneventful.

Among the clinical parameters examined, there was a lower mean grade of inflammation present in patients treated successfully with ETGBD relative to patients in whom ETGBD was unsuccessful (mean CRP value $5.4 \mathrm{mg} / \mathrm{dL}$ versus $10.9 \mathrm{mg} / \mathrm{dL}$, respectively; $\mathrm{P}$ not significant). None of the other clinical factors, including age, sex, period from admission to ETGBD, and history of cholecystitis or biliary colic, correlated significantly with the success of ETGBD (Table 1).

Examination of gallbladder ultrasonogram records revealed two patients who were ineligible for ETGBD. One had gallbladder cancer that resulted in irregular thickening of the gallbladder wall, and the other had no ultrasonographic records. Among the remaining nine patients, cases without a distended gallbladder or sonolucent layer (Table 2), and those with a shorter gallbladder major axis (70.6 mm versus $92.3 \mathrm{~mm}$ ) showed a greater tendency toward ETGBD success (P not significant) (Figure 3). The frequency of success was significantly higher in patients with a shorter gallbladder minor axis 
TABLE 1

Clinical and laboratory variables for 11 patients who underwent endoscopic transpapillary gallbladder drainage (ETGBD)

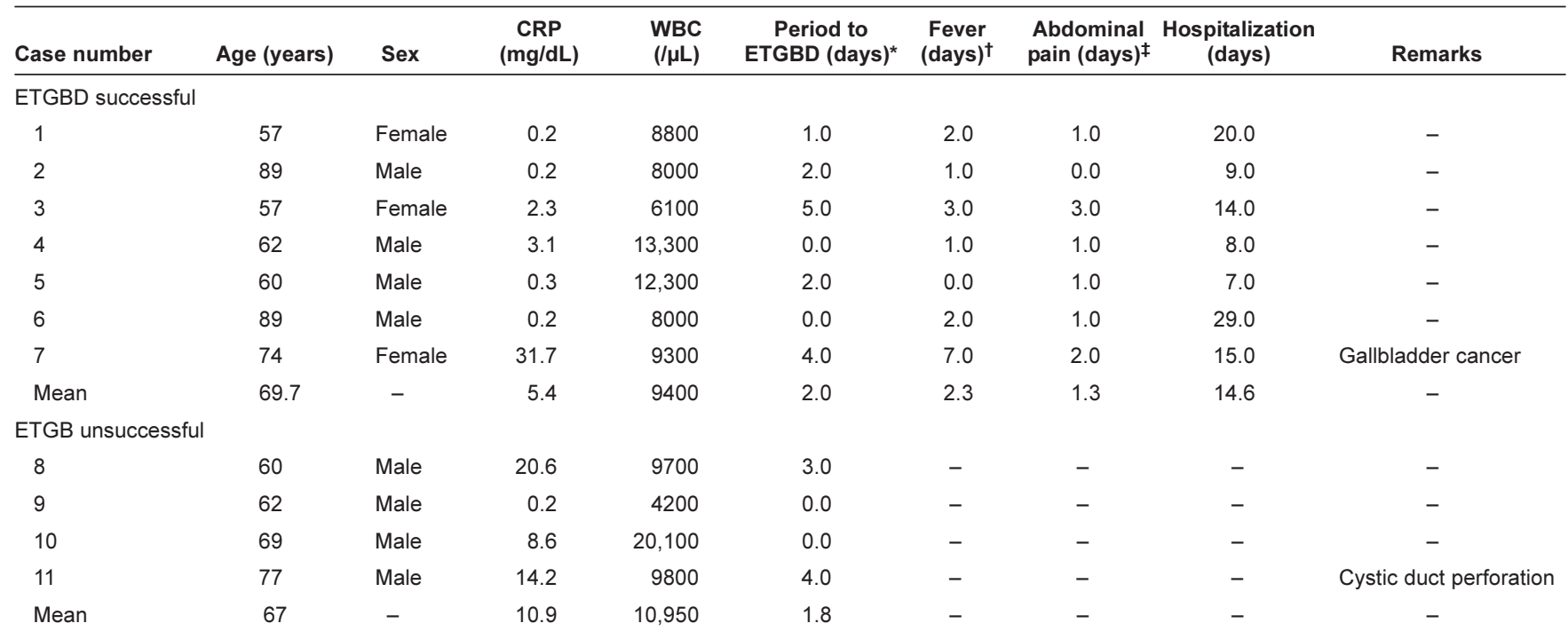

In ETGBD-unsuccessful patients, period to ETGBD, fever, abdominal pain and hospitalization were not applicable because ETGBD was not successful (and percutaneus transhepatic gallbladder drainage was performed). *Period to ETGBD is the period from admission to performance of ETGBD; ${ }^{\dagger}$ Fever was the duration of fever; ${ }^{\ddagger}$ Abdominal pain was the duration of abdominal pain. CRP C-reactive protein on admission; WBC White blood cell count on admission

TABLE 2

Ultrasonographic findings for nine patients* who underwent endoscopic transpapillary gallbladder drainage (ETGBD)

\begin{tabular}{|c|c|c|c|c|c|c|c|}
\hline Case number & $\begin{array}{l}\text { Sonographic } \\
\text { Murphy sign }\end{array}$ & Enlargement & $\begin{array}{c}\text { Sonolucent } \\
\text { layer }\end{array}$ & $\begin{array}{c}\text { Major } \\
\text { axis }(\mathrm{mm})\end{array}$ & $\begin{array}{c}\text { Minor } \\
\text { axis }(\mathrm{mm})\end{array}$ & $\begin{array}{c}\text { Wall } \\
\text { thickness (mm) }\end{array}$ & Remarks \\
\hline \multicolumn{8}{|c|}{ ETGBD successful } \\
\hline 1 & $(+)$ & $(-)$ & $(-)$ & 40.0 & 30.0 & 5.3 & - \\
\hline 2 & $(+)$ & $(+)$ & $(-)$ & 85.0 & 35.0 & 5.4 & - \\
\hline 3 & $(+)$ & $(-)$ & $(-)$ & 62.0 & 24.0 & 2.0 & - \\
\hline 4 & $(+)$ & $(+)$ & $(-)$ & 77.0 & 25.0 & 4.1 & - \\
\hline \multicolumn{8}{|c|}{ ETGBD unsuccessful } \\
\hline 8 & $(+)$ & $(+)$ & $(+)$ & 105.0 & 35.0 & 14.0 & - \\
\hline 9 & $(+)$ & $(+)$ & $(+)$ & 83.0 & 36.0 & 7.0 & - \\
\hline 10 & $(+)$ & $(+)$ & $(-)$ & 93.0 & 41.0 & 4.9 & - \\
\hline 11 & $(+)$ & $(+)$ & $(+)$ & 88.0 & 40.0 & 10.2 & Cystic duct perforation \\
\hline
\end{tabular}

*Two of the 11 cases were ineligible for ETGBD. These included case number 6, with no ultrasonographic records; and case number 7 , due to gallbladder cancer. (-) Not present; (+) Present

(27.4 mm versus $38.0 \mathrm{~mm}$; $\mathrm{P}=0.008$ ) (Figure 4) and thinner gallbladder wall (4.2 mm versus $9.0 \mathrm{~mm} ; \mathrm{P}=0.041)$ (Figure 5).

These data demonstrate that ultrasonographic findings, particularly gallbladder minor-axis length and wall thickness, can contribute significantly to the prediction of potential technical difficulties associated with ETGBD. Ultrasonographic findings also suggest that ETGBD can be more difficult to perform in patients with a longer gallbladder minor axis or thicker gallbladder wall.

\section{DISCUSSION}

The results of the present study demonstrate that ultrasonography is the best method for predicting potential ETGBD technical difficulties during pretreatment evaluation of patients with acute cholecystitis. ETGBD success is most likely in patients with mild cholecystitis who present with a short gallbladder minor axis or thin gallbladder wall.

Over the past 15 years, several studies $(8,9,11,12)$ have reported ETGBD to be a viable treatment option for acute cholecystitis. Despite these reports, ETGBD technical difficulties contribute significantly to variable success rates $(54 \%$ to $89 \%$ ), including $63.6 \%$ in the present study. Because variable rates of success are likely due to differences in the severity of acute cholecystitis among the patients in each study, accurate pretreatment evaluation of patients is an important predictor of ETGBD success.

Although the severity of acute cholecystitis is commonly assessed from laboratory data (13-15), analyses of pretreatment 


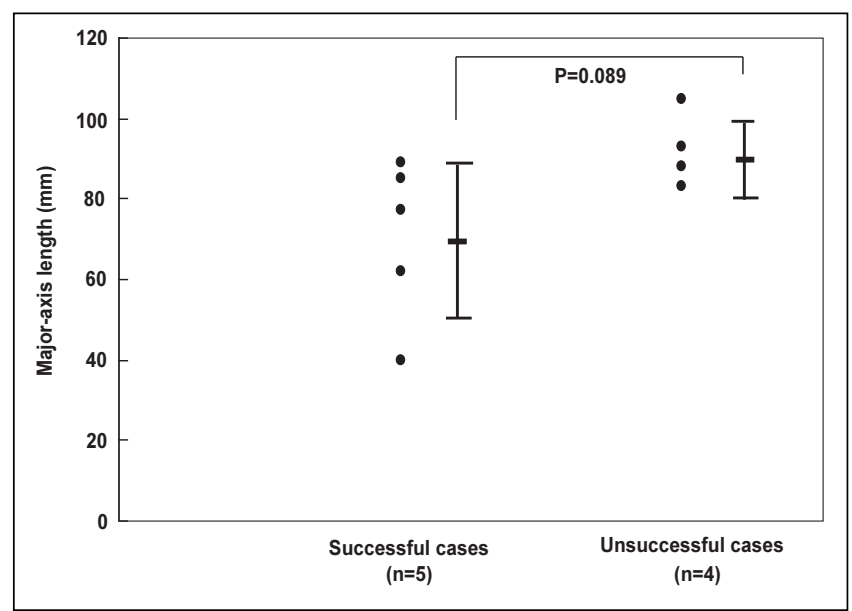

Figure 3) Comparison of gallbladder major-axis dimensions in successful versus unsuccessful endoscopic transpapillary gallbladder drainage. Although there was a tendency toward a shorter average major-axis length of gallbladders in successful cases relative to unsuccessful cases, the difference was not significant $(70.6 \mathrm{~mm}$ versus $92.3 \mathrm{~mm}$, respectively; $P=0.089$ )

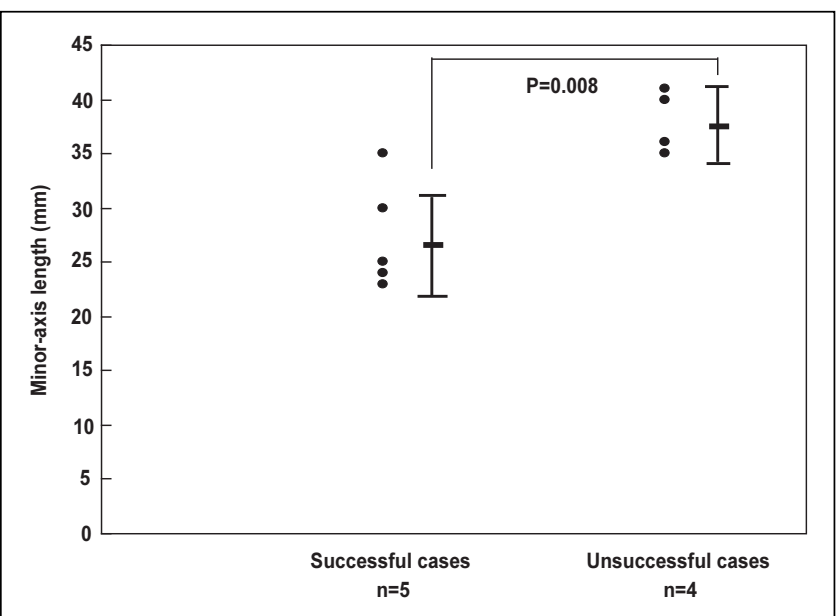

Figure 4) Comparison of gallbladder minor-axis dimensions in successful versus unsuccessful endoscopic transpapillary gallbladder drainage. The average minor-axis length of gallbladders was significantly shorter in successful cases relative to unsuccessful cases (27.4 $\mathrm{mm}$ versus $38.0 \mathrm{~mm}$, respectively; $P=0.008$ )

evaluations in the present study demonstrate that laboratory data and patient background are not associated significantly with ETGBD success. In contrast, findings from gallbladder ultrasonograms appear to depict gallbladder health more accurately and are significant predictors of ETGBD success.

Among ultrasonogram dimensions examined, gallbladder minor-axis length and wall thickness were most predictive of ETGBD success. Ultrasonogram data suggest that cholecystitis associated with a longer minor axis or thicker gallbladder wall is more severe and can result in more difficult cystic duct cannulation due to inflammation in patients with severe cholecystitis.

These data suggest that ETGBD is an appropriate treatment option for patients with mild cholecystitis and that the procedure should be performed at early acute onset of cholecystitis

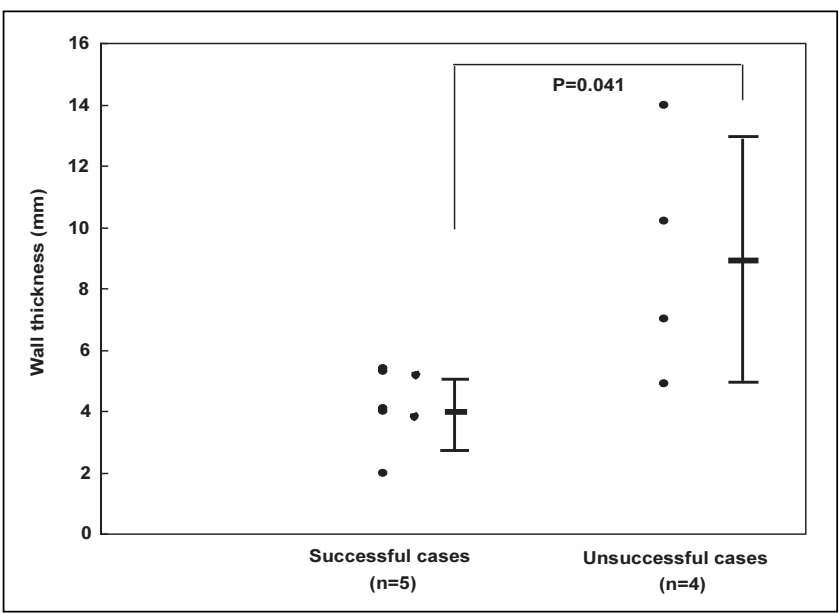

Figure 5) Comparison of gallbladder wall thickness in successful versus unsuccessful endoscopic transpapillary gallbladder drainage. The average gallbladder wall thickness was significantly thinner in successful cases relative to unsuccessful cases $(4.2 \mathrm{~mm}$ versus $9.0 \mathrm{~mm}$, respectively; $P=0.041$ )

to maximize efficiency and success. Patients with postendoscopic retrograde cholangiopancreatography cholecystitis or biliary colic are appropriate candidates for ETGBD. For patients with postendoscopic retrograde cholangiopancreatography cholecystitis, ETGBD should be performed at the early acute onset stage, when the condition of the biliary and cystic ducts has been recently evaluated. In patients with biliary colic, PTGBD should be avoided due to liver and gallbladder adhesions, which can increase the difficulty of performing cholecystectomy.

\section{CONCLUSIONS}

Ultrasonographic findings of the gallbladder, particularly minor-axis length and wall thickness, are significant predictors of ETGBD-associated technical difficulties and should be evaluated before patients with acute cholecystitis are treated.

ACKNOWLEDGEMENTS: The authors express their gratitude to Dr Rikiya Fujita for his detailed comments and suggestions.

\section{REFERENCES}

1. Margiotta SJ Jr, Horwitz JR, Willis IH, Wallack MK. Cholecystectomy in the elderly. Am J Surg 1988;156:509-12.

2. Puggioni A, Wong LL. A metaanalysis of laparoscopic cholecystectomy in patients with cirrhosis. J Am Coll Surg 2003;197:921-6.

3. Chopra S, Dodd GD III, Mumbower AL, et al. Treatment of acute cholecystitis in non-critically ill patients at high surgical risk: Comparison of clinical outcomes after gallbladder aspiration and after percutaneous cholecystostomy. AJR Am J Roentgenol 2001;176:1025-31.

4. Hadas-Halpern I, Patlas M, Knizhnik M, Zaghal I, Fisher D. Percutaneous cholecystostomy in the management of acute cholecystitis. Isr Med Assoc J 2003;5:170-1.

5. Byrne MF, Suhocki P, Mitchell RM, et al. Percutaneous cholecystostomy in patients with acute cholecystitis: Experience of 45 patients at a US referral center. J Am Coll Surg 2003;197:206-11.

6. Spira RM, Nissan A, Zamir O, Cohen T, Fields SI, Freund HR. Percutaneous transhepatic cholecystostomy and delayed 
laparoscopic cholecystectomy in critically ill patients with acute calculus cholecystitis. Am J Surg 2002;183:62-6.

7. vanSonnenberg E, D'Agostino HB, Goodacre BW, Sanchez RB, Casola G. Percutaneous gallbladder puncture and cholecystostomy: Results, complications, and caveats for safety. Radiology 1992;183:167-70

8. Toyota N, Takada T, Amano H, Yoshida M, Miura F, Wada K. Endoscopic naso-gallbladder drainage in the treatment of acute cholecystitis: Alleviates inflammation and fixes operator's aim during early laparoscopic cholecystectomy. J Hepatobiliary Pancreat Surg 2006;13:80-5.

9. Kjaer DW, Kruse A, Funch-Jensen P. Endoscopic gallbladder drainage of patients with acute cholecystitis. Endoscopy 2007;39:304-8

10. Trowbridge RL, Rutkowski NK, Shojania KG. Does this patient have acute cholecystitis? JAMA 2003;289:80-6.
11. Feretis C, Apostolidis N, Mallas E, Manouras A, Papadimitriou J. Endoscopic drainage of acute obstructive cholecystitis in patients with increased operative risk. Endoscopy 1993;25:392-5.

12. Kanemaki. [Clinical study of endoscopic transpapillary gallbladder drainage for cystic duct obstruction by impacted gallstones.] Gastroenterological Endoscopy 1996;38:1047-56

13. Thompson JE Jr, Bennion RS, Doty JE, Muller EL, Pitt HA. Predictive factors for bactibilia in acute cholecystitis. Arch Surg 1990;125:261-4.

14. Merriam LT, Kanaan SA, Dawes LG, et al. Gangrenous cholecystitis: Analysis of risk factors and experience with laparoscopic cholecystectomy. Surgery 1999;126:680-5; discussion 685-6.

15. Hirota M, Takada T, Kawarada Y, et al. Diagnostic criteria and severity assessment of acute cholecystitis: Tokyo Guidelines. J Hepatobiliary Pancreat Surg 2007;14:78-82. 


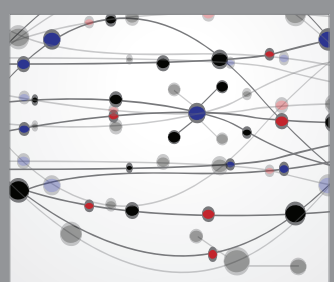

The Scientific World Journal
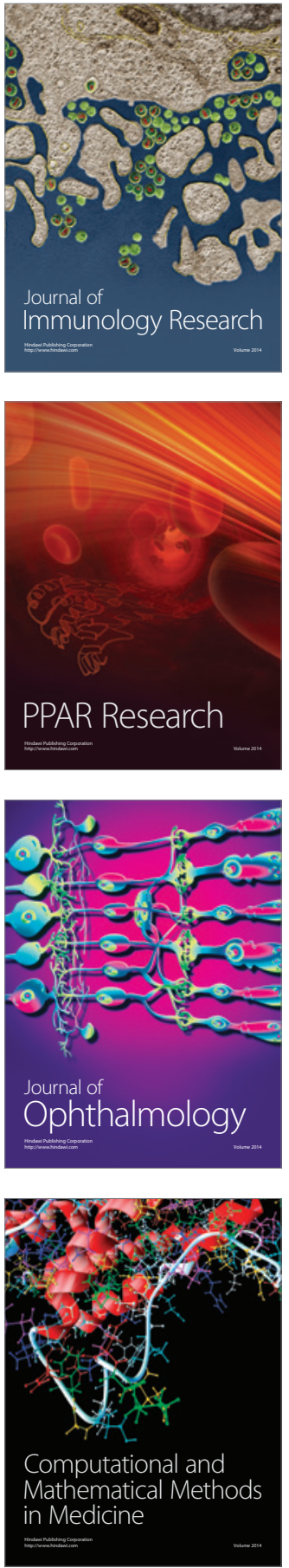

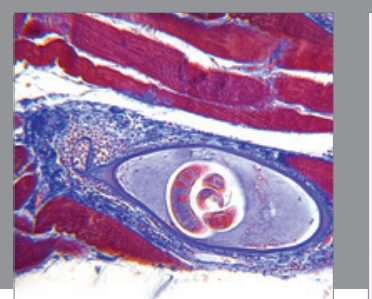

Gastroenterology Research and Practice

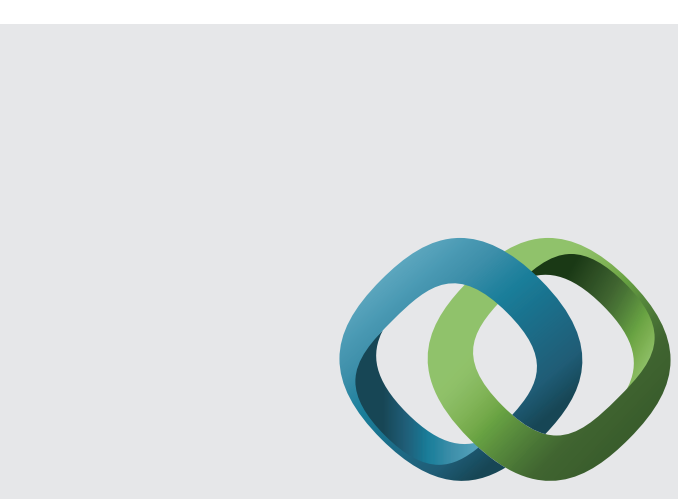

\section{Hindawi}

Submit your manuscripts at

http://www.hindawi.com
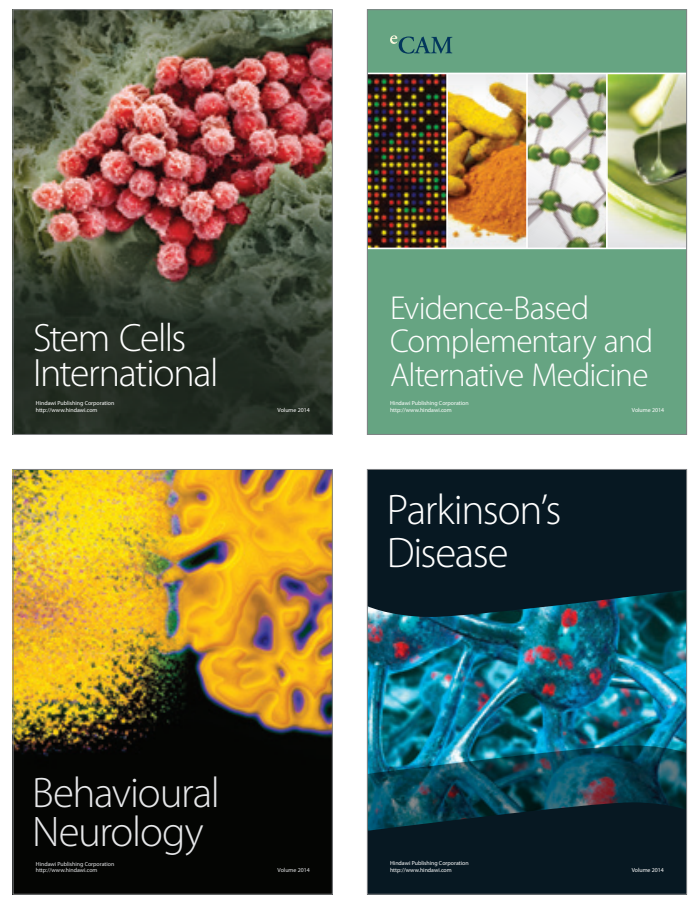
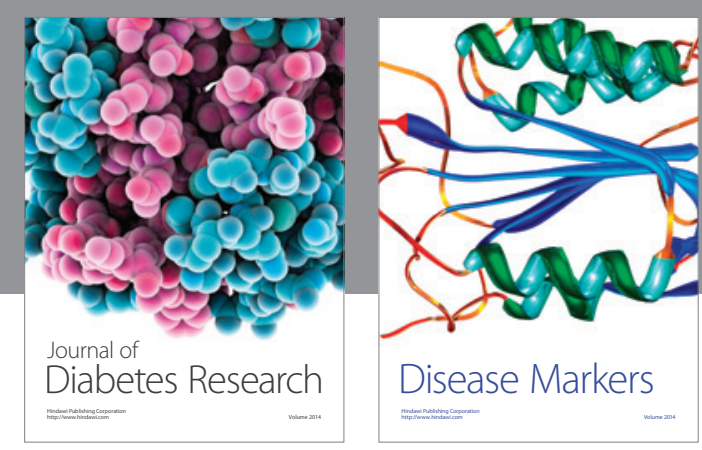

Disease Markers
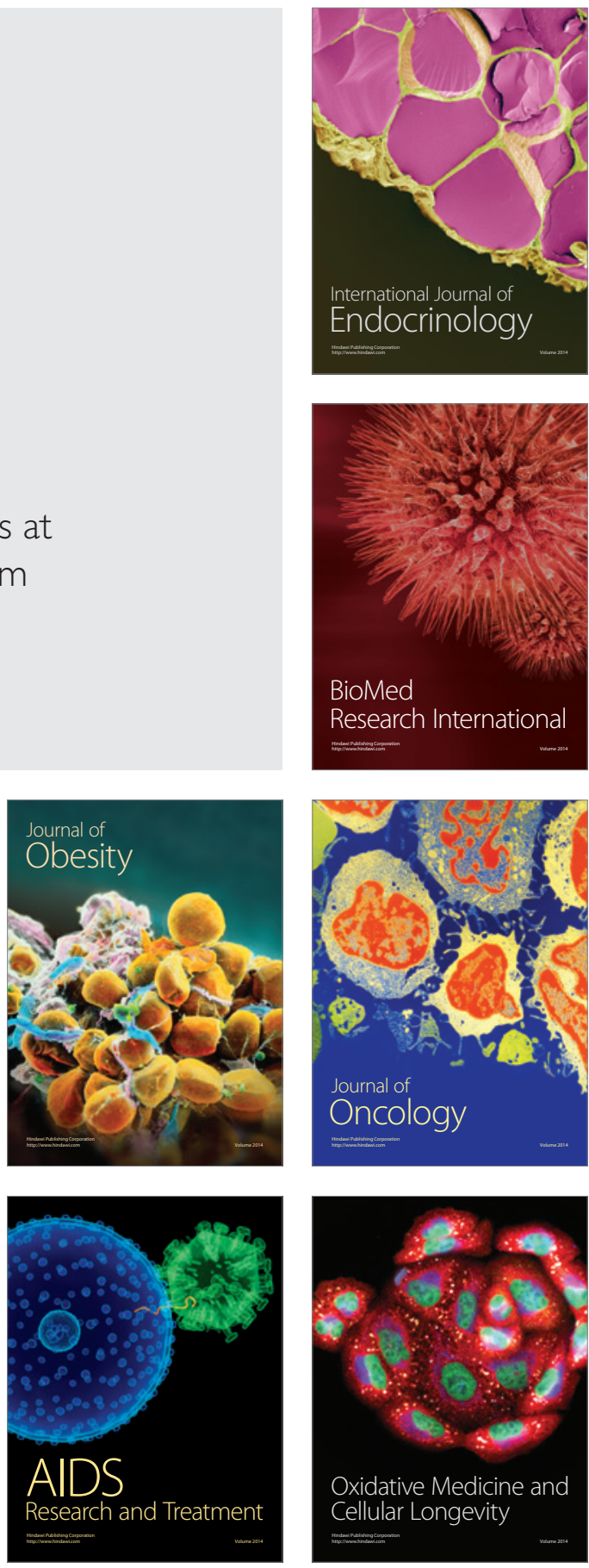